\title{
Skin malformations in a neonatal foal tested homozygous positive for Warmblood Fragile Foal Syndrome
}

\author{
Chloé Monthoux ${ }^{1}$, Simone de Brot ${ }^{2,3}$, Michelle Jackson $^{4}$, Ulrich Bleul ${ }^{1}$ and Jasmin Walter ${ }^{{ }^{*}}$
}

\begin{abstract}
Background: Skin malformations that resembled manifestations of Ehlers-Danlos-Syndrome were described in a variety of domestic animals during the last century as cutis hyperelastica, hyperelastosis cutis, dermatosparaxis, dermal/collagen dysplasia, dermal/cutaneous asthenia or Ehlers-Danlos-like syndrome/s. In 2007, the mutation responsible for Hereditary Equine Regional Dermal Asthenia (HERDA) in Quarter Horses was discovered. Several case reports are available for similar malformations in other breeds than Quarter Horses (Draught Horses, Arabians, and Thoroughbreds) including four case reports for Warmblood horses. Since 2013, a genetic test for the Warmblood Fragile Foal Syndrome Type 1 (WFFS), interrogating the causative point mutation in the equine procollagen-lysine, 2-oxoglutarate 5-dioxygenase 1 (PLOD1, or lysyl hydroxylase 1) gene, has become available. Only limited data are available on the occurrence rate and clinical characteristics of this newly detected genetic disease in horses. In humans mutations in this gene are associated with Ehlers-Danlos Syndrome Type VI (kyphoscoliotic form).

Case presentation: This is the first report describing the clinical and histopathological findings in a foal confirmed to be homozygous positive for WFFS. The Warmblood filly was born with very thin, friable skin, skin lesions on the legs and the head, and an open abdomen. These abnormalities required euthanasia just after delivery. Histologic examination revealed abnormally thin dermis, markedly reduced amounts of dermal collagen bundles, with loosely orientation and abnormally large spaces between deep dermal fibers.
\end{abstract}

Conclusion: WFFS is a novel genetic disease in horses and should be considered in cases of abortion, stillbirth, skin lesions and malformations of the skin in neonatal foals. Genetic testing of suspicious cases will contribute to evaluate the frequency of occurrence of clinical WFFS cases and its relevance for the horse population.

Keywords: PLOD1, Equine procollagen-lysine, 2-oxoglutarate 5-dioxygenase 1, LH1, Lysyl hydroxylase 1, Ehlers-Danlos syndrome, Dermatosparaxis, Dermal hyperfragility, Horse, Equine, Connective tissue, Hereditary

\section{Background}

A hereditary disease with symptoms of hyperextensible and abnormally fragile skin, as well as hyperextensibility of articulations, was first described in humans in 1892 [1]. The name Ehlers-Danlos Syndrome (EDS) was proposed in 1934 to describe this disease complex [2]. This syndrome is caused by various mutations with different modes of heredity and was categorized into different subtypes because of variation in affection of blood vessels, internal organs, wound healing and impact on the

\footnotetext{
* Correspondence: jwalter@vetclinics.uzh.ch

${ }^{1}$ Clinic of Reproductive Medicine, Vetsuisse Faculty, University of Zurich,

Winterthurerstrasse 260, 8057 Zurich, Switzerland

Full list of author information is available at the end of the article
}

pregnancy, additional to the typical lesions on skin and joints [3-5].

EDS-like diseases have been described for decades in cat [6], dog [7], rabbit [8], mink [7], cattle [9], sheep [10] and horse $[9,11]$, with variable heredity in the different species. These syndromes were commonly described as cutis hyperelastica, hyperelastosis cutis, dermatosparaxis, dermal/collagen dysplasia, dermal/cutaneous asthenia or Ehlers-Danlos-like syndrome/s [8,9,11-17].

" Ehlers-Danlos-like syndromes" (EDLS) will be used in this paper to describe the syndromes in animals, in which the clinical findings are similar to human EDS, independent of their origin. 
In several cases of EDLS in different species, mutations were detected in genes encoding for enzymes involved in production of collagen or other components of the dermal extracellular matrix $[2,12,13,18-22]$.

In equines, EDLS are described in Draught horses [14], Warmblood horses [9,15,23,24], Arabians [25], Quarter Horses and Quarter lineage [16,26-37] as well as Thoroughbreds [11]. These syndromes were described in neonates, juveniles and adults. Two gene defects causing an EDLS phenotype in horses have been discovered in recent years. Since 2007, the test for the well documented hereditary equine regional dermal asthenia (HERDA) in Quarter Horses and related breeds, testing for the known PPIB:p.39Gly > Arg mutation of the peptidylprolyl isomerase B (cyclophilin B) gene, is available [13,16,31-36,38].

For Warmblood Fragile Foal Syndrome Type 1 (WFFS), a genetic test developed by $\mathrm{N}$. Winand became commercially available in $2013^{\mathrm{a}}$ [39]. This autosomal recessive inherited disease occurs in Warmblood horses and related breeds and is reportedly caused by a point mutation (c.2032G > A, p.Gly678Arg) in the equine procollagenlysine, 2-oxoglutarate 5-dioxygenase 1 (PLOD1) gene [39].

PLOD1 is an important posttranslational modifying enzyme in collagen biosynthesis, which hydroxylates specific lysines in collagen [19]. These hydroxylysines act as precursors for crosslinking that are responsible for the tensile strength, mechanical stability of collagen fibrils and are involved in the formation of fibers $[4,19,21]$. Plod1 knock-out mice are flaccid, have gait abnormalities and about $15 \%$ of them die because of aortic rupture. Smooth muscle cells in non-ruptured Plod1 ${ }^{-/}$aortas showed degenerative changes and collagen fibrils in the Plod1 $1^{-1}$ aorta and skin showed abnormal morphology [40]. Over 20 different mutations have been reported for the human PLOD1 gene and are associated with clinical EhlerDanlos-Syndrome type VI, also called the kyphoscoliotic type, with the most common human mutation $(25 \%)$ being a duplication of exons 10-16 [19-21,41]. Ten human pathogenic variants were point mutations in different exon regions of PLOD1, which were also shown to be associated with a decreased enzyme activity in Ehler-Danlos Type VI patients [21]. Symptoms of this autosomal recessive inherited connective tissue fragility syndrome occur from birth on and are characterized by skin hypersensibility, muscle hypotonia, joint laxity, eyes and vessels involvement, scoliosis and premature rupture of fetal membranes [3,4,18-21,41-43]. Life span of these patients may be normal, but affected individuals are at risk for rupture of medium sized arteries $[4,19]$.

The decreased activity of PLOD1 leads to reduced hydroxylysine-based pyridinoline cross-links in collagens and therefore to an increased lysylpyridinoline (LP) to hydroxylysylpyridinoline (HP) ratio in urine, which is used to diagnose kyphoscoliotic EDS VI [4]. Another method to test these patients for EDS, kyphoscoliotic form, is the measurement of PLOD1 enzyme activity in cultured fibroblasts $[4,19]$.

Mutations in the PLOD1 gene were not described in animals up to the patent application for the WFFS test [39]. To our knowledge, this is the first case report describing the clinical and histopathological changes in a genetically confirmed homozygous WFFS foal.

\section{Case presentation}

A 5-year-old Westfalian Warmblood mare was referred to the Clinic of Reproductive Medicine for dystocia in March 2012. During pregnancy, no complications were detected and parturition occurred near the calculated date of term. The obstetrical examination revealed a living foal in cranial presentation, dorso-sacral position, with bilateral carpal flexion. Correction of carpal flexion was not possible in the standing mare, resulting in the decision to perform a controlled vaginal delivery under general anaesthesia. Ten minutes after induction of anaesthesia, correction of bilateral carpal flexion was possible after elevation of the mare's hindquarters. A living filly was extracted after solely manual correction with slight traction. The foal presented with an open abdomen and extensive skin lesions (Figure 1). Obstetrical devices were not used for the gentle correction and extraction procedure, which makes idiopathic causes for the injuries unlikely. The newborn was euthanized due to poor prognosis and a full necropsy was performed. The mare was released from the clinic in healthy condition after treatment for retained foetal membranes.

\section{Pathological findings}

On macroscopic necropsy examination, the foal presented with multiple extensive (up to $20 \mathrm{~cm}$ in length) and severe skin lacerations on both front legs and face. The abdomen was open on midline measuring approximately $30 \mathrm{~cm}$ in length with eventration of the small intestines.

In the affected areas, the skin was extremely fragile and thin ( 1 to $2 \mathrm{~mm}$ ), friable and very loosely attached to the underlying subcutaneous tissue (Figure 2). Pressure points on head as well as front and hind limbs showed subcutaneous oedema, hematomas and seromas, particulary affected were the fetlocks and tarsus regions.

Several samples of lesional and non-lesional skin were fixed in $10 \%$ neutral buffered formalin, paraffin-embedded, sectioned at $3 \mu \mathrm{m}$, and stained with haematoxylin and eosin (HE) for light microscopy. On histologic examination, the abnormally thin dermis showed a markedly reduced amount of dermal collagen bundles that were of variable thickness and orientation and loosely arranged with abnormally large spaces between deep dermal fibers. The epidermis and adnexal structures were normal (Figure 3). 



Figure 1 Clinical presentation of the WFFS foal. The foal presented with severe ablation of skin on the right front leg (above) and an open abdomen and eventration of the small intestines (below).

Electron microscopy (EM) was performed on affected skin samples from various locations of the body. For negative contrast EM, selected tissues were fixed in 2.5\% glutaraldehyde and 1\% osmium tetroxide (OsO4) and buffered with $0.1 \mathrm{M}$ sodium phosphate ( $\mathrm{pH}$ 7.4). After fixation, the tissues were dehydrated in an ethanol series, embedded in Epoxy resin ${ }^{\mathrm{b}}$, cut in ultrathin $(90 \mathrm{~nm}) \mathrm{sec}-$ tions and stained with uranyl acetate and lead citrate.

EM examination revealed only mild abnormalities. The collagen fibrils were reasonably well organised in bundles forming parallel arrays and showed regular periodic banding. However, mild randomness in orientation and mild variability of the cross-sections of the collagen fibrils were present (Figure 3).

\section{Genetic tests}

At the time of necropsy, the only available genetic test for EDLS was the test for HERDA, for which the mare was homozygous negative. In spring 2013, when the WFFS-test became commercially available ${ }^{\mathrm{a}}$, the mare was tested and resulted heterozygous positive for the WFFS allele $(A / G)$. The stallion was not tested. Consequently, formalin fixed muscle tissue of the foal was also submitted for genetic testing. Genomic DNA was extracted from muscle tissue using the commercially available MagNA Pure 96 DNA and Viral NA Small Volume Kit ${ }^{\mathrm{c}}$ following manufacturers' instructions. Genotyping was performed for the XM_001491331:c.2032G > A variant in the PLOD1 gene, which is supposed to be the causative variant for 


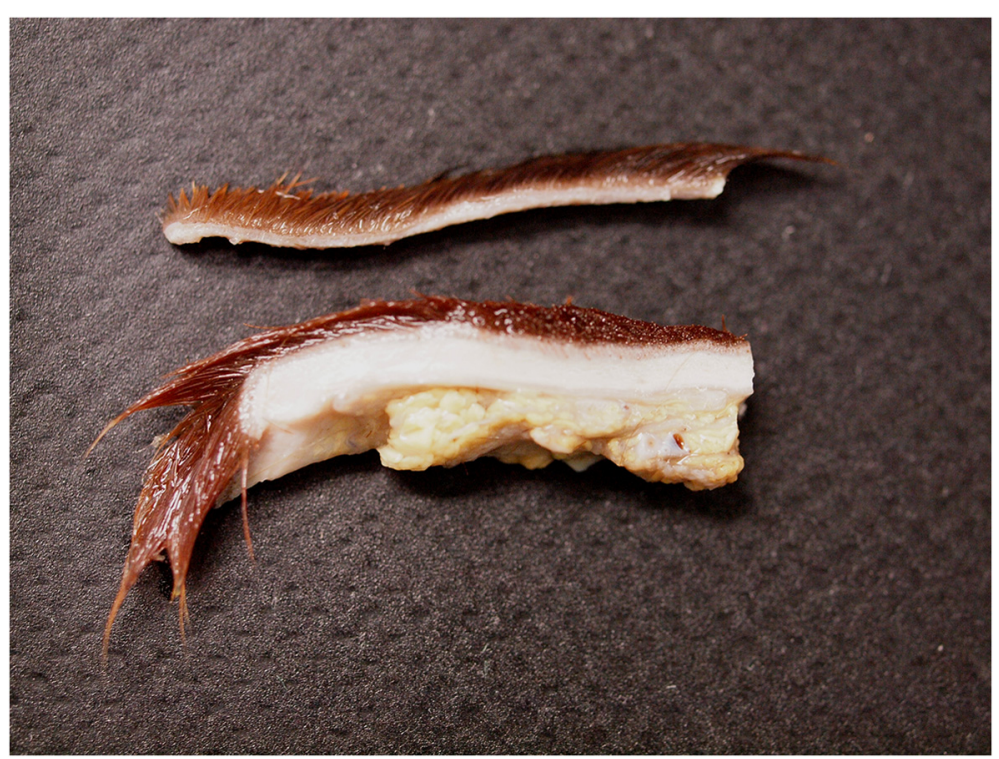

Figure 2 Skin morphology of the WFFS foal. Affected skin from the front limb (above) is markedly thinner $(<1.5 \mathrm{~mm})$ than unaffected skin from the back (below) of the same foal.

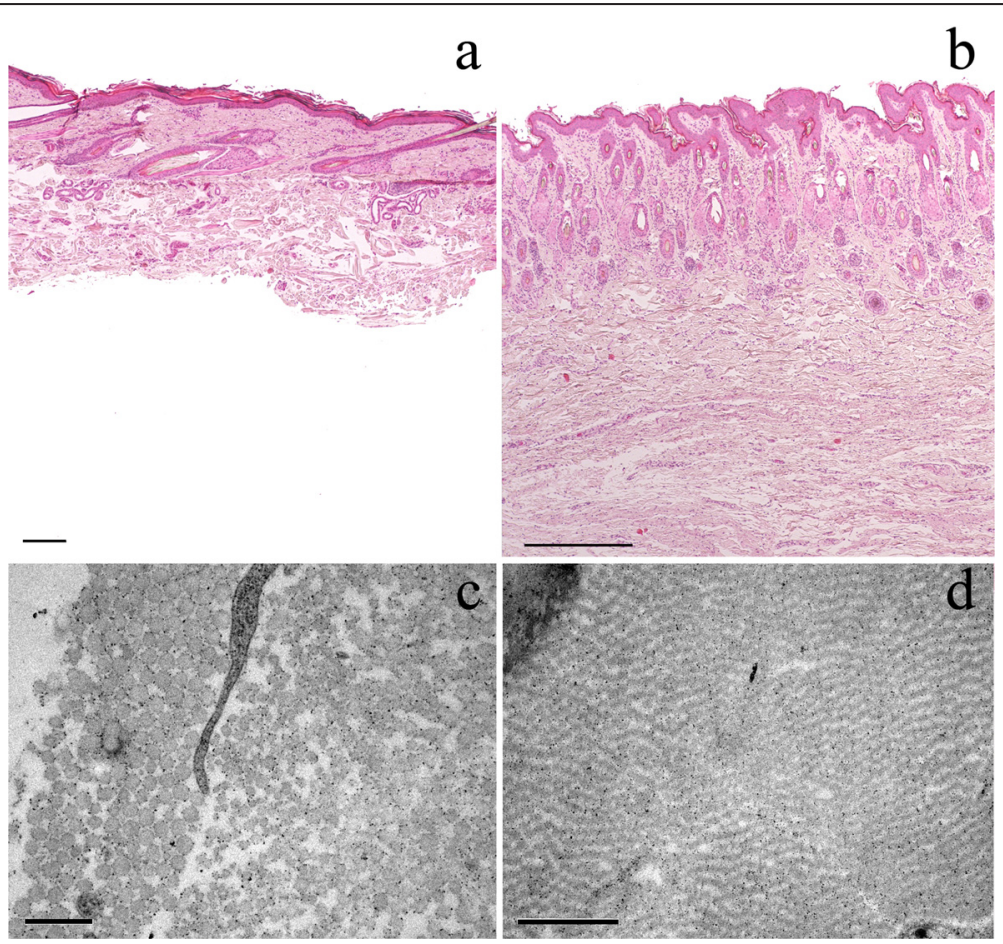

Figure 3 Light and electron microscopy of affected (a\&c) and unaffected (b\&d) skin. Light microscopy of affected (a) and unaffected (b) skin: The deep dermis is markedly thinned (approximately 30\% of dermal thickness of hind limb skin of unaffected 1-day-old control Warmblood foal (b)) and shows a reduced number of thin, irregular collagen bundles separated by clear spaces. The epidermis and adnexal structures appear normal. Subcutaneous tissue was detached from the overlying dermis and is missing on this slide. The size bars indicate $200 \mu \mathrm{m}$. Haematoxylin and eosin staining (HE), 4x. Electron microscopy of affected (c) and unaffected (d) skin: In the affected skin (c) (front limb) a mild randomness in orientation and variability of the cross-sections of the collagen fibrils are present. The size bar indicates $0.5 \mu \mathrm{m}$. The skin of the control (d) (hind limb from a 1-day-old control Warmblood foal) shows regular orientation of collagen fibrils with no visible variability of cross-sections. The size bar indicates $1 \mu \mathrm{m}$. 
Warmblood Fragile Foal Syndrome type 1 (WFFS) according to the patent application [39] (primers and PCR conditions available from Laboklin, Bad Kissingen, Germany upon request). The results revealed a homozygous positive WFFS $(A / A)$ genotype for the foal. Close relatives to the foal, all healthy, were also tested for the WFFS genotype and revealed either a carrier genotype ( $A / G$; two tested half-sisters of the foal sired by the same stallion) or a homozygous wild type genotype $(G / G$; two mothers of the heterozygous half-sisters and the full sister of the mother of the homozygous positive and symptomatic foal) (Figure 4). All samples for genetic analysis were submitted to the laboratory without mentioning clinical suspicion for WFFS. The Clinic of Reproductive Medicine and the owner of the horses were fully charged for all tests.

\section{Discussion}

Case reports about EDLS describing clinical, histological and EM findings in horses were well recorded this past decade, but usually without any genetic confirmation as HERDA and WFFS tests were not available. Now, after the discovery of two genetic causes, previous cases may be explained by the newly detected mutations.

The majority of published EDLS case reports in horses describe the clinical signs of HERDA mutation in the Quarter Horse. Nevertheless, there are several EDLS cases documented in other breeds than Warmblood or Quarter horses [11,14,25]. These horses presented with several of the following symptoms: skin hyperelasticity; loss of the hoof capsule; lesions on the back, the flanks, shoulders and legs; pathologic scar formation; and abortion or embryonic loss in related pairings $[11,14,25]$.

Literature of HERDA homozygous symptomatic horses, after the launch of the genetic test in 2007 [13,31-33], enabled the description of a more precise phenotype for this mutation: fragile and hyperextensible skin, lacerations, seromas, haematomas, ulcerations and scars with typical localisation on the dorsal region extending to other parts of the body [16]. The disease may also affect other tissues, such as tendons, ligaments, great vessels or the cornea. These clinical signs most commonly emerge in older horses; however, documentation of neonatal cases exist [16].

Genetically confirmed WFFS cases were not available in previous literature; however, four case reports of EDLS clinical signs in Warmblood horses have been reported $[9,15,23,24]$. The first two cases in neonates (one and six days old) showed skin lesions on the limbs, abdominal region, withers and underneath the tail, with hyperextension of the limb articulations, hydrops, subcutaneous emphysema, and a general modified integument $[9,23]$. In another case report, a 6-weekold foal developed haematomas, multiple lacerations, scars and oedema and displayed poor wound healing with skin lesions localised on the flank, stifle and limb regions [15]. Regarding age (1.5 years) and localisation of lesions, the last case is atypical. In this case, the horse displayed wound-healing problems and dermatological modifications of the skin and hair on the flank and back. The dorsal skin, lateral to the thoracolumbar region, was hyperelastic and painful [24]. Retrospectively, these four

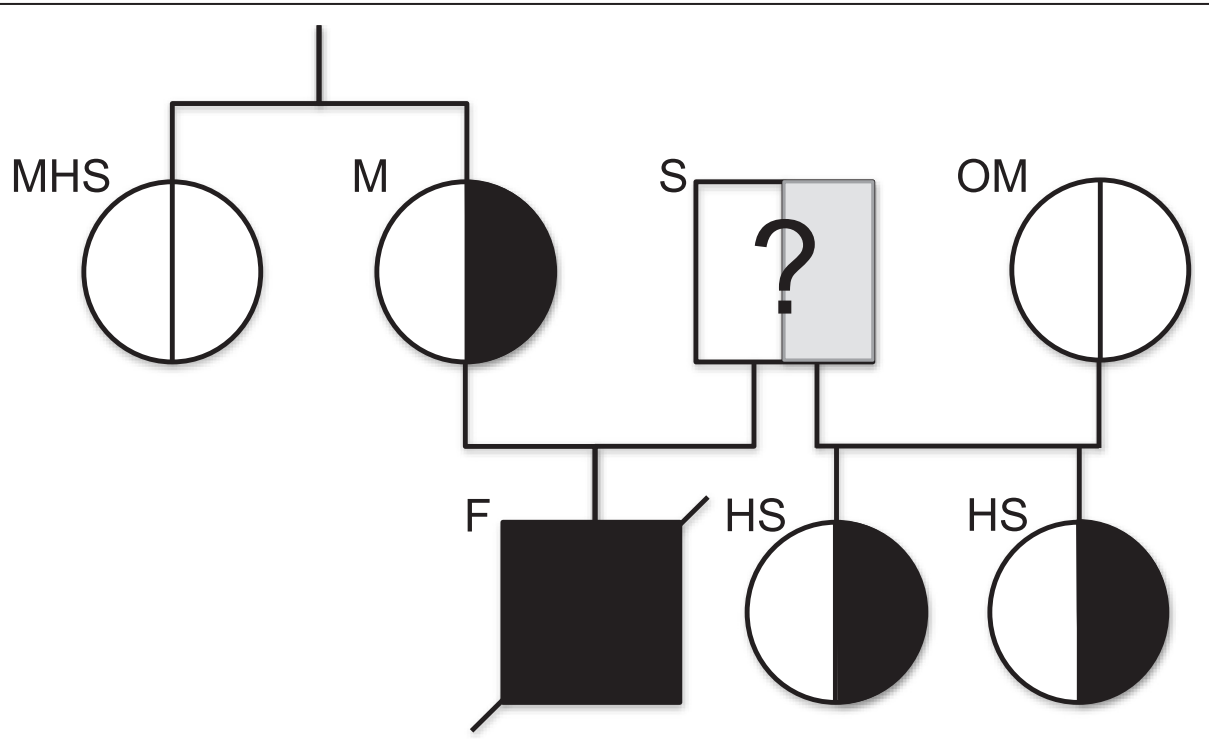

Figure 4 Results of the genetic testing of the foal and close relatives. WFFS carriers in the relatives of the homozygous foal are the mare (M) and two of his half-sisters (HS) from the same stallion (S). The mothers of the half-sisters (OM) and the mare's half-sister (MHS) were homozygous for the wild-type allele. The stallion was not tested for WFFS. 
clinical cases without association to a specific genotype are now suspicious for WFFS. As suggested by Steelman (2013), EDLS in horses seems to be a collection of similar phenotypes with different genetic origin [36], so differentiation between HERDA, WFFS and other EDLS cases is difficult without genetic testing (Table 1).

Necropsy alone appears insufficient to diagnose one of the EDLS types, as many similarities were observed in the lesions of our positive tested WFFS case, the cases retrospectively suspicious for WFFS and other documented EDLS cases. Additionally, it is unclear if other atypical phenotypes exist for this disease. Perhaps the birth of foals with cutaneous malformations is not the only clinical presentation. In humans, EDS symptomatic fetuses of asymptomatic mothers were affected by premature birth, still birth and abortion [18,42-47]. As the foetal membranes find their origin in the embryo, the connective tissue in these membranes may also be affected and leading to their premature rupture, causing the above described complications of pregnancy [44]. These clinical manifestations of cases with similar causative mechanism can lead to the suggestion that cases of abortion, still birth and premature labour may also be caused by WFFS, even when there are no case reports available. Widespread genetic testing, especially of abortions and symptomatic offspring of heterozygous (A/G) pairings, will help to obtain a more detailed description of the clinical signs that may be caused by this mutation.

Detailed information about the prevalence of the WFFS mutation is not available in the literature. The human EDSVI is rare with a disease incidence of approximately 1:100,000 live births and an estimated carrier frequency of 1:150 $[19,20]$. The patent application for the test describes test results of 124 horses. The carrier frequency in the tested clinically normal adult Warmblood population was $11.11 \%$. Perfect association between homozygosity $(A / A$, $\mathrm{n}=2$ ) and clinical WFFS symptoms was observed. Heterozygous $(A / G, \mathrm{n}=8)$ and wild type homozygous $(G / G$, $\mathrm{n}=114$ ) animals were all phenotypically normal. The carrier frequency in the initial test population was corroborated by the data of 500 randomly selected Warmblood horses in Germany, where $9.5 \%$ of the population were detected as carriers (Personal Communication: Gunreben B. ${ }^{a}$; 2013). The seven horses tested for this case report reflect these results with regard to association between genotype and phenotype: a clinical phenotype was observed solely in the homozygous positive foal. Up to now, no reports are available for genetically confirmed homozygous

Table 1 Synoptical table for congenital skin lesions and malformations in horses

\begin{tabular}{|c|c|c|c|}
\hline Disease & WFFS & HERDA & EDLS \\
\hline Full Name & Warmblood Fragile Foal Syndrome & $\begin{array}{l}\text { Hereditary Equine Regional Dermal } \\
\text { Asthenia }\end{array}$ & $\begin{array}{l}\text { Ehlers-Danlos-like syndrome of } \\
\text { unknown origin }\end{array}$ \\
\hline Breed & Warmblood & $\begin{array}{l}\text { Quarter Horse (lineage: stallion } \\
\text { Poco Bueno) }\end{array}$ & $\begin{array}{l}\text { Warmblood, Quarter horse, Drafthorse, } \\
\text { Arabian, Thoroughbred }\end{array}$ \\
\hline Gene & $\begin{array}{l}\text { PLOD1: "procollagen-lysine, } \\
\text { 2-oxoglutarate 5-dioxygenase } \\
\text { 1" (LH1: lysyl hydrohylase 1) }\end{array}$ & $\begin{array}{l}\text { PPIB: "peptidyl-prolyl cis-trans } \\
\text { isomerase B" } \\
\text { (Cyclophilin B) }\end{array}$ & $\begin{array}{l}\text { Involved genes not elucidated up to } \\
\text { now }\end{array}$ \\
\hline Symptoms & $\begin{array}{l}\text { Lesions of skin/mucosa (tearing, } \\
\text { ulcerations); Hyperextension } \\
\text { of articulations, } \\
\text { floppy ears, hydrops, } \\
\text { subcutaneous emphysema, } \\
\text { hematomas, premature birth }\end{array}$ & $\begin{array}{l}\text { Fragile and hyper extensible skin, } \\
\text { lacerations, seromas, hematomas, } \\
\text { ulcerations, scars }\end{array}$ & $\begin{array}{l}\text { Skin hyper elasticity, loss of hoof } \\
\text { capsule, lesions on back, flanks, } \\
\text { shoulders, legs, scarring, pregnancy } \\
\text { loss, retention of fetal membranes }\end{array}$ \\
\hline Localisation of lesions & $\begin{array}{l}\text { Head, neck, thorax, legs, abdomen, } \\
\text { stifle, withers, perineum, oral mucous } \\
\text { membranes, articular cartilage }\end{array}$ & $\begin{array}{l}\text { Back and from back extending, may } \\
\text { involve: tendons, ligaments, great } \\
\text { vessels, cornea }\end{array}$ & Variable \\
\hline Age & Most common in neonates & $\begin{array}{l}\text { Mostly older horses, also possible } \\
\text { in neonates }\end{array}$ & Neonates as well as adult horses \\
\hline Heredity & Autosomal recessive & Autosomal recessive & Heredity mode not described \\
\hline Genetic testing available & Yes & Yes & No \\
\hline Prevalence of mutation & $\begin{array}{l}\text { Up to } 11.11 \% \text { in clinically normal } \\
\text { adult Warmblood horses }\end{array}$ & Prevalence up to $28.3 \%$ in Cutting horses & Prevalence unknown \\
\hline \multirow[t]{4}{*}{ Data sources } & Patent application & Ishikawa et al. (2012) [13] & Gunson et al. (1984) [25] \\
\hline & Winand N (2012) & Mochal et al. (2010) [33] & Esser M. et al. (1999) [19] \\
\hline & & Grady et al. (2009) [32] & $\begin{array}{l}\text { Solomons B (1984) [11], } \\
\text { Rufenacht S et al. (2010) [24] }\end{array}$ \\
\hline & & & Steelman et al. (2013) [36] \\
\hline
\end{tabular}


positive animals for the WFFS mutation with absence of clinical symptoms.

\section{Conclusions}

Due to the severe clinical signs, this novel genetic disease requires further investigation to obtain robust data on prevalence of the mutation as well as the correlation between genotype and phenotype. Homozygous $(A / A)$ offspring can be avoided from now on easily by breeding heterozygous carriers only to homozygous negative breeding partners. Awareness for this new disease will hopefully result in the genetic testing of suspicious cases as identification of homozygous animals provides the unique opportunity to study the biochemical and clinical consequences of the mutation to obtain an in-depth characterization of WFFS.

\section{Endnotes}

\section{Manufacturers' details}

${ }^{a}$ Laboklin GmbH\&Co.KG, Bad Kissingen, Germany

${ }^{\mathrm{b}}$ Epon, Fluka, Sigma-Aldrich, St-Louis, MO, USA

${ }^{\mathrm{c}}$ Roche Diagnostics International AG, Rotkreuz, Switzerland.

\section{Abbreviations}

EDS: Ehlers-Danlos syndrome; EDLS: Ehlers-Danlos-like syndromes; EDSVI: Ehlers-Danlos syndrome type Vl; HERDA: Hereditary equine regional dermal asthenia; LH1: Lysyl hydroxylase 1; PLOD1: Procollagen-lysine, 2-oxoglutarate 5-dioxygenase 1; PPIB: Peptidylprolyl isomerase B (cyclophilin B); WFFS: Warmblood fragile foal syndrome type 1.

\section{Competing interests}

The authors declare that they have no competing interests.

\section{Authors' contributions}

CM drafted the manuscript and created the diagram, table and figures; SDB did the macroscopic, histopathological and electron microscopic examination, drafted the respective part of the manuscript and provided the gross (Figure 2) and microscopical (Figure 3) pictures; MJ was the responsible surgeon for this case and provided pictures of the foal; UB provided helpful discussions and final corrections on the manuscript: JW treated the obstetrical case, initiated genetic testing, drafted parts of the manuscript and revised it critically. All authors read and approved the final version of this manuscript.

\section{Acknowledgements}

We thank Tosso Leeb (Institute of Genetics, Vetsuisse Faculty, University of Bern) for helpful discussions on this manuscript and Lisbeth Nufer (Institute of Veterinary Pathology, Vetsuisse Faculty, University of Zurich) for performing electron microscopy.

\section{Author details}

${ }^{1}$ Clinic of Reproductive Medicine, Vetsuisse Faculty, University of Zurich, Winterthurerstrasse 260, 8057 Zurich, Switzerland. ${ }^{2}$ Institute of Veterinary Pathology, Vetsuisse Faculty, University of Zurich, Winterthurerstrasse 260, 8057 Zurich, Switzerland. ${ }^{3}$ Current address: School of Veterinary Medicine and Science, University of Nottingham, Sutton Bonington LE12 5RD, UK. ${ }^{4}$ Equine Department, Section Surgery, Vetsuisse Faculty, University of Zurich, Winterthurerstrasse 260, 8057 Zurich, Switzerland.

Received: 31 July 2014 Accepted: 5 January 2015

Published online: 31 January 2015

\section{References}

1. Tschernogubow A. Über einen Fall von Cutis laxa. (Presentation at the first meeting of Moscow Dermatologic and Venerologic Society, Nov 13, 1891). In: Mhft Prakt Derm. Hamburg: Leopold Voss; 1892. P. 76.

2. Burrows NP. The molecular genetics of the Ehlers-Danlos syndrome. Clin Exp Dermatol. 1999;24:99-106.

3. Beighton P, De Paepe A, Steinmann B, Tsipouras P, Wenstrup RJ. Ehlers-Danlos syndromes: revised nosology, Villefranche, 1997. Ehlers-Danlos National Foundation (USA) and Ehlers-Danlos Support Group (UK). Am J Med Genet. 1998;77:31-7.

4. De Paepe A, Malfait F. The Ehlers-Danlos syndrome, a disorder with many faces. Clin Genet. 2012:82:1-11.

5. Byers PH, Murray ML. Heritable collagen disorders: the paradigm of the Ehlers-Danlos syndrome. J Invest Dermatol. 2012;132:E6-11.

6. Freeman $\amalg$, Hegreberg GA, Robinette JD. Ehlers-Danlos syndrome in dogs and cats. Semin Vet Med Surg (Small Anim). 1987;2:221-7.

7. Hegreberg GA, Padgett GA, Gorham JR, Henson JB. A connective tissue disease of dogs and mink resembling the Ehlers-Danlos syndrome of man. II. Mode of inheritance. J Hered. 1969;60:249-54.

8. Sinke JD, van Dijk JE, Willemse T. A case of Ehlers-Danlos-like syndrome in a rabbit with a review of the disease in other species. Vet Q. 1997;19:182-5.

9. Witzig P, Suter M, Wild P, Rao VH, Steinmann B, Von Rotz A. Dermatosparaxis in a foal and a cow-a rare disease? Schweiz Arch Tierheilkd. 1984;126:589-96.

10. Helle $\mathrm{O}, \mathrm{Nes} N \mathrm{~N}$. A hereditary skin defect in sheep. Acta Vet Scand. 1972;13:443-5

11. Solomons B. Equine cutis hyperelastica. Equine Vet J. 1984;16:541-2.

12. Bellini MH, Caldini ET, Scapinelli MP, Simoes MJ, Machado DB, Nurmberg R. Increased elastic microfibrils and thickening of fibroblastic nuclear lamina in canine cutaneous asthenia. Vet Dermatol. 2009;20:139-43.

13. Ishikawa Y, Vranka JA, Boudko SP, Pokidysheva E, Mizuno K, Zientek K, et al. Mutation in cyclophilin B that causes hyperelastosis cutis in American Quarter Horse does not affect peptidylprolyl cis-trans isomerase activity but shows altered cyclophilin B-protein interactions and affects collagen folding. J Biol Chem. 2012;287:22253-65.

14. Esser $M$, Niederacher $V$, Pfeffer $K$, Scheuer $H$. über die selten auftretende Dermatosparaxie (Ehlers-Danlos-Syndrom) bei einem Fohlen - ein Fallbericht. Pferdeheilkunde. 1999;15:434-6.

15. Marshall VL, Secombe C, Nicholls PK. Cutaneous asthenia in a Warmblood foal. Aust Vet J. 2011:89:77-81.

16. Rashmir-Raven A. Heritable equine regional dermal asthenia. Vet Clin North Am Equine Pract. 2013;29:689-702.

17. Rodriguez F, Herraez P, Espinosa de los Monteros A, Calabuig P, Rodriguez $J$ L. Collagen dysplasia in a litter of Garafiano shepherd dogs. Zentralbl Veterinarmed A. 1996:43:509-12.

18. Ehlers-Danlos Syndrome, Kyphoscoliotic Form [http://www.ncbi.nlm.nih.gov/ books/NBK1462/]

19. Yeowell HN, Walker LC. Mutations in the lysyl hydroxylase 1 gene that result in enzyme deficiency and the clinical phenotype of Ehlers-Danlos syndrome type VI. Mol Genet Metab. 2000;71:212-24

20. Giunta C, Randolph A, Steinmann B. Mutation analysis of the PLOD1 gene: an efficient multistep approach to the molecular diagnosis of the kyphoscoliotic type of Ehlers-Danlos syndrome (EDS VIA). Mol Genet Metab. 2005;86:269-76.

21. Walker LC, Overstreet MA, Siddiqui A, De Paepe A, Ceylaner G, Malfait F, et al. A novel mutation in the lysyl hydroxylase 1 gene causes decreased lysyl hydroxylase activity in an Ehlers-Danlos VIA patient. J Invest Dermatol. 2005;124:914-8

22. Lapiere CM, Lenaers A, Kohn LD. Procollagen peptidase: an enzyme excising the coordination peptides of procollagen. Proc Natl Acad Sci U S A. 1971;68:3054-8.

23. Winter T, Börgel C, Aupperle H, Schoon HA. Eine dem Ehlers-Danlos Syndrom des Menschen ähnliche Bindegewebserkrankung der Haut bei einem Fohlen. Pferdeheilkunde. 2004;20:19-22.

24. Rufenacht S, Straub R, Steinmann B, Winand N, Bidaut A, Stoffel MH, et al. Swiss warmblood horse with symptoms of hereditary equine regional dermal asthenia without mutation in the cyclophylin B gene (PPIB). Schweiz Arch Tierheilkd. 2010;152:188-92.

25. Gunson DE, Halliwell RE, Minor RR. Dermal collagen degradation and phagocytosis. Occurrence in a horse with hyperextensible fragile skin. Arch Dermatol. 1984;120:599-604. 
26. White SD, Affolter VK, Bannasch DL, Schultheiss PC, Hamar DW, Chapman $P L$, et al. Hereditary equine regional dermal asthenia ("hyperelastosis cutis") in 50 horses: clinical, histological, immunohistological and ultrastructural findings. Vet Dermatol. 2004;15:207-17.

27. White SD, Affolter VK, Schultheiss PC, Ball BA, Wessel MT, Kass P, et al. Clinical and pathological findings in a HERDA-affected foal for 1.5 years of life. Vet Dermatol. 2007;18:36-40.

28. Hardy MH, Fisher KR, Vrablic OE, Yager JA, Nimmo-Wilkie JS, Parker W, et al. An inherited connective tissue disease in the horse. Lab Invest. 1988;59:253-62.

29. Lerner DJ, McCracken MD. Hyperelastosis cutis in 2 Horses. J Equine Med Surgery. 1978;2:350-2.

30. Brounts SH, Rashmir-Raven AM, Black SS. Zonal dermal separation: a distinctive histopathological lesion associated with hyperelastosis cutis in a Quarter Horse. Vet Dermatol. 2001;12:219-24.

31. Bowser JE, Elder SH, Pasquali M, Grady JG, Rashmir-Raven AM, Wills R, et al. Tensile properties in collagen-rich tissues of Quarter Horses with hereditary equine regional dermal asthenia (HERDA). Equine Vet J. 2014;46:216-22.

32. Grady JG, Elder SH, Ryan PL, Swiderski CE, Rashmir-Raven AM. Biomechanical and molecular characteristics of hereditary equine regional dermal asthenia in Quarter Horses. Vet Dermatol. 2009;20:591-9.

33. Mochal CA, Miller WW, Cooley AJ, Linford RL, Ryan PL, Rashmir-Raven AM. Ocular findings in Quarter Horses with hereditary equine regional dermal asthenia. J Am Vet Med Assoc. 2010;237:304-10.

34. Tryon RC, Penedo MC, MCCue ME, Valberg SJ, Mickelson JR, Famula TR, et al Evaluation of allele frequencies of inherited disease genes in subgroups of American Quarter Horses. J Am Vet Med Assoc. 2009;234:120-5.

35. Finno CJ, Spier SJ, Valberg SJ. Equine diseases caused by known genetic mutations. Vet J. 2009:179:336-47.

36. Steelman SMJND, Conant E, Juras R, Cothran EG, Edwards JF, Chowdhary BP. Ehlers-Danlos syndrome in a Quarter Horse gelding: a case report of PPIB-independent HERDA. J Equine Vet Sci. 2013;34:565-8.

37. Borges AS, Conceicao LG, Alves AL, Fabris VE, Pessoa MA. Hereditary equine regional dermal asthenia in three related Quarter horses in Brazil. Vet Dermatol. 2005;16:125-30.

38. Badial PR, Oliveira-Filho JP, Winand NJ, Borges AS. Allele frequency of hereditary equine regional dermal asthenia in American Quarter horses in Brazil determined by quantitative real-time PCR with high resolution melting analysis. Vet J. 2014;199:306-7.

39. Winand N. Identification of the causative mutation for inherited connective tissue disorders in equines. "United States Department Of Commerce Application Number: 61/486,464; (Filing Date: May 16th, 2011)." Available at http://patentscope.wipo.int/search/en/detail.jsf?docld=WO2012158711 \&recNum $=1$ \&maxRec $=1$ \&office= \&prevFilter $=$ \&sortOption=Pub+Date +Desc\&queryString=FP\%3A\%28WO2012158711\%29\&tab=PCT+Biblio

40. Takaluoma K, Hyry M, Lantto J, Sormunen R, Bank RA, Kivirikko Kl, et al. Tissue-specific changes in the hydroxylysine content and cross-links of collagens and alterations in fibril morphology in lysyl hydroxylase 1 knock-out mice. J Biol Chem. 2007:282:6588-96.

41. Wenstrup RJ, Murad S, Pinnell SR. Ehlers-Danlos syndrome type VI: clinical manifestations of collagen lysyl hydroxylase deficiency. J Pediatr. 1989;115:405-9.

42. Pinnell SR, Krane SM, Kenzora JE, Glimcher MJ. A heritable disorder of connective tissue. Hydroxylysine-deficient collagen disease. N Engl J Med. 1972;286:1013-20

43. Krieg T, Feldmann U, Kessler W, Muller PK. Biochemical characteristics of Ehlers-Danlos syndrome type VI in a family with one affected infant. Hum Genet. 1979;46:41-9.

44. Barabas AP. Ehlers-Danlos syndrome: associated with prematurity and premature rupture of foetal membranes; possible increase in incidence. Br Med J. 1966:2:682-4.

45. Pope FM, Narcisi P, Nicholls AC, Liberman M, Oorthuys JW. Clinical presentations of Ehlers Danlos syndrome type IV. Arch Dis Child. 1988;63:1016-25.

46. Levick K. Pregnancy loss and fathers with Ehlers-Danlos syndrome. Lancet. 1989:2:1151.

47. Fujimoto A, Wilcox WR, Cohn DH. Clinical, morphological, and biochemical phenotype of a new case of Ehlers-Danlos syndrome type VIIC. Am J Med Genet. 1997:68:25-8.

\section{Submit your next manuscript to BioMed Central and take full advantage of:}

- Convenient online submission

- Thorough peer review

- No space constraints or color figure charges

- Immediate publication on acceptance

- Inclusion in PubMed, CAS, Scopus and Google Scholar

- Research which is freely available for redistribution 